\title{
Molecular Characterization and Phylogenetic Relationships of Plant-Parasitic Nematodes Associated with Turfgrasses in North Carolina and South Carolina, United States
}

\begin{abstract}
Yongsan Zeng, Department of Plant Protection, Zhongkai University of Agriculture and Engineering, Guangzhou, 510225, People's Republic of China; Department of Plant Pathology, North Carolina State University, Raleigh 27695; Weimin Ye, Nematode Assay Section, Agronomic Division, North Carolina Department of Agriculture and Consumer Services, Raleigh 27607; James Kerns and Lane Tredway, Department of Plant Pathology, North Carolina State University, Raleigh; Samuel Martin, School of Agricultural, Forest and Environmental Sciences, Pee Dee Research \& Education Center, Florence, SC 29506; and Matt Martin, Crop Science Department, North Carolina State University, Castle Hayne 28429
\end{abstract}

\begin{abstract}
Zeng, Y., Ye, W., Kerns, J., Tredway, L., Martin, S., and Martin, M. 2015. Molecular characterization and phylogenetic relationships of plant-parasitic nematodes associated with turfgrasses in North Carolina and South Carolina, United States. Plant Dis. 99:982-993.

The near-full-length $18 \mathrm{~S}$ ribosomal DNA (rDNA) gene and internal transcribed spacer 1 region were amplified and sequenced from 52 nematode populations belonging to 28 representative species in 13 families recovered from turfgrasses in North Carolina (38 populations) and South Carolina (14 populations). This study also included 13 nematode populations from eight other plant hosts from North Carolina for comparison. Nematodes were molecularly characterized and the phylogenetic relationships were explored based on 18S rDNA sequences. Phylogenetic analysis using Bayesian inference was performed using five groups of the plantparasitic nematode populations Tylenchids, Criconematids, Longidorids,

Xiphinematids, and Trichodorids. The 65 nematode populations were clustered correspondingly within appropriate positions of 13 families, including Belonolaimidae, Caloosiidae, Criconematidae, Dolichodoridae, Hemicycliophoridae, Hoplolaimidae, Heteroderidae, Longidoridae, Meloidogynidae, Paratylenchidae, Pratylenchidae, Telotylenchidae, and Trichodoridae. This study confirms previous morphological-based identification of the plant-parasitic nematode species found in turfgrasses and provides a framework for future studies of plant-parasitic nematodes associated with turfgrasses based upon DNA sequences and phylogenetic relationships.
\end{abstract}

Turfgrass (multiple species) beautifies home lawns and provides safe playing surfaces on athletic fields, outdoor recreation, and economic opportunities for tens of thousands of seed and sod producers, lawn care operators and landscapers. There are approximately $35,850 \mathrm{~km}^{2}$ of managed turfgrasses in the United States (Milesi et al. 2005). This places turfgrass third in total agricultural crop acreage nationwide (http://www.ntep.org/pdf/turfinitiative.pdf). Turfgrass is the number one or two agricultural commodity in many states such as Maryland, Pennsylvania, Florida, New Jersey, and North Carolina (http://www.ntep.org/pdf/turfinitiative.pdf). However, maintenance of turfgrass is very challenging due to economic pressures, damage by pests, and changes in the availability of pesticides. Of the pests that impact turfgrass, plant-parasitic nematodes are often overlooked and, therefore, have become a serious problem in turfgrass. During a survey from 2010 to 2013, 29 species of plant-parasitic nematodes belonging to 22 genera in 15 families were found associated with the turfgrasses bermudagrass (Cynodon dactylon), creeping bentgrass (Agrostis stolonifera), and zoysiagrass (Zoysia japonica) in North Carolina and South Carolina (Zeng et al. 2012b). Of the plant-parasitic nematodes found in the survey, Belonolaimus longicaudatus, Cactodera sp. Dolichodorus heterocephalus, Hemicycliophora spp., Hoplolaimus galeatus, Meloidogyne spp., Mesocriconema spp., Paratrichodorus spp., and Xiphinema spp. were the most frequently encountered and damaging species (Ye et al. 2012). From this research, damage thresholds where control actions should be taken were proposed (Ye et al. 2012).

Corresponding author: J. Kerns; E-mail: jpkerns@ncsu.edu

Accepted for publication 27 January 2015.

http://dx.doi.org/10.1094/PDIS-10-14-1060-RE

(C) 2015 The American Phytopathological Society
Morphological identification of plant-parasitic nematodes associated with turfgrass is difficult because of the presence of many similar morphological characteristics in species such as Cactodera sp., Hemicriconemoides spp., Hemicycliophora spp., Helicotylenchus spp., Meloidogyne spp., Mesocriconema spp., Ogma spp., and Pratylenchus spp. Moreover, the diagnostic life stages, such as females for Meloidogyne spp. and Cactodera sp., are usually not available in communities extracted from soil samples. However, accurate identification and pathogenic characterization of nematodes attacking turfgrasses are needed as an initial step in designing effective control measures or in searching for possible sources of host-plant resistance against plant-parasitic nematodes found in turfgrass.

Molecular systematics is a valuable tool in modern nematode taxonomy (Subbotin et al. 2005, 2006; Ye et al. 2007). Studies of phylogenetic relationships among nematodes are not only essential to taxonomy but also allow for a more complete understanding of the biology of nematodes as agricultural pests (Subbotin et al. 2001). DNA sequence data from the $18 \mathrm{~S}$ ribosomal DNA (rDNA), internal transcribed spacer (ITS), and 28SrDNA, as well as mitochondrial DNA (mtDNA), are the most frequently used genomic regions in phylogenetic studies of plant-parasitic nematodes due to ubiquitous occurrence and essential functions (Blaxter et al. 1998; Duarte et al. 2010; Gutiérrez-Gutiérrez et al. 2013; Kumari and Subbotin 2012; McClure et al. 2012; Subbotin et al. 2001, 2005, 2006; Van Megen et al. 2009; Vovlas et al. 2008; Ye et al. 2007). The $18 \mathrm{~S}$ and ITS regions are frequently used for both phylogenetic analyses and diagnostic purposes because the $18 \mathrm{~S}$ region is conserved while the ITS region is more variable. The conserved region allows for sequences from divergent taxa to be easily aligned, provides a valuable tool for distinguishing taxa, and also enables the design of universal primers (Dorris et al. 1999). Near-full-length sequences of the $18 \mathrm{~S}$ and ITS for nematodes can be amplified by polymerase chain reaction (PCR). For this reason, these regions are very popular among molecular systematists for phylogenetic investigation 
of many nematodes (Kanzaki and Giblin-Davis 2014; Turbeville et al. 1991; Ye et al. 2007).

Currently, molecular information on plant-parasitic nematodes associated with turfgrass is limited. Nischwitz et al. (2013) characterized two species of Meloidogyne (namely, Meloidogyne fallax and M. minor) using 28S D2/D3 and ITS regions and analyzed, based upon heat shock protein 90 (Hsp90), phylogenetic relationships among five species of Meloidogyne, including M. fallax, M. minor, M. chitwoodi, $M$. naasi, and $M$. hapla from golf course putting greens in the western United States. McClure et al. (2012) molecularly identified Meloidogyne spp. from 110 golf course greens by phylogenetically analyzing sequences from 18S, 28S D2/D3, ITS rDNA, mtDNA cytochrome oxidase subunit I, and 16S rRNA gene sequences. Molecular data has been applied in a few studies such as those describing a new species or for diagnosing nematodes associated with turfgrass (Inserra et al. 2013b; Salazar et al. 2013; Shaver et al. 2013; Zeng et al. 2012a; Zhuo et al. 2011).

In North Carolina and South Carolina, with more than 1,000 golf courses, turfgrass is a major industry. There were approximately 30 plant-parasitic nematode species recovered during our previous survey (Zeng et al. 2012b) but no data on molecular characterization of and phylogenetic relationships among these nematodes are available. The objectives of this study were to (i) molecularly characterize 52 plant-parasitic nematode populations belonging to 28 species collected from turfgrasses in North Carolina and South Carolina using the near-full-length 18S rDNA gene and ITS1 rDNA region and (ii) investigate the phylogenetic relationships among these plant-parasitic nematode species and verify previous morphological-based identification of these species (Zeng et al. 2012b) with analysis of 18S rDNA sequences.

\section{Materials and Methods}

Plant-parasitic nematode populations. In total, 282 soil samples were collected during a plant-parasitic nematode survey of 111 golf courses in 39 counties in North Carolina and South Carolina during summer 2011 (Zeng et al. 2012b). Each sample consisted of 12 soil cores $(1.5 \mathrm{~cm}$ in diameter by $20 \mathrm{~cm}$ deep) sampled at roughly equal intervals in a zig-zag pattern across an area of $1,000 \mathrm{~m}^{2}$ or less. Soil samples were placed in sealed plastic bags, which were then placed in sample boxes and stored at $4^{\circ} \mathrm{C}$ until analysis. Nematodes were extracted from soil samples by a combination of elutriation (Byrd et al. 1976) and centrifugation (Jenkins 1964) methods. The present study selected 52 representative plant-parasitic nematode populations belonging to 20 genera and 28 species in 13 families for molecular characterization. Two families (Tylenchidae and Aphelenchoidae) were not characterized due to limited specimens and lack of DNA. Thirteen populations of species within the Tylenchidae and Aphelenchoidae families from other hosts in North Carolina were included for phylogenetic comparison (Table 1).

DNA extraction. For molecular analysis, a single nematode or up to 10 nematodes from the same sample were hand picked into $10 \mu \mathrm{l}$ of AE buffer (10 mM Tris-Cl and 0.5 mM EDTA, pH 9.0) on a glass microscope. Nematodes were identified to species using a compound microscope and keys proposed by Siddiqi (2000) and Decraemer (1995). Identified nematodes were then macerated with a pipette tip, collected in $50 \mu \mathrm{l}$ of $\mathrm{AE}$ buffer, and stored at $-20^{\circ} \mathrm{C}$.

DNA amplification, cleaning, and sequencing. The primers used for PCR and DNA sequencing are presented in Table 2. Primers SSUF07/SSUR26 (Floyd et al. 2002), 18S965/18S1573R (Mullin et al. 2005), and 18SnF/18SnR (Kanzaki and Futai 2002) were used to amplify the $18 \mathrm{~S}$ gene. The primers rDNA2 (Vrain et al. 1992) and rDNA1.58S (Cherry et al. 1997) were used to amplify the ITS1 rDNA region. A 25- $\mu 1$ PCR was performed using Apex Taq Red Master Mix DNA polymerase (Genesee Scientific Corporation, San Diego, $\mathrm{CA}$ ) according to the manufacturer's protocol. The thermal cycler program for PCR was as follows: denaturation at $95^{\circ} \mathrm{C}$ for $6 \mathrm{~min}$ followed by 40 cycles of denaturation at $95^{\circ} \mathrm{C}$ for $30 \mathrm{~s}$, annealing at $50^{\circ} \mathrm{C}$ for $30 \mathrm{~s}$, and extension at $72^{\circ} \mathrm{C}$ for $1 \mathrm{~min}$. A final extension was performed at $72^{\circ} \mathrm{C}$ for $10 \mathrm{~min}$ (Ye et al. 2007). PCR products were cleaned using ExoSap-IT (Affymetrix, Inc., Santa Clara, CA) according to the manufacturer's protocol. DNA sequencing was performed using PCR primers for direct sequencing by dideoxynucleotide chain termination using an ABI PRISM BigDye terminator cycle sequencing ready reaction kit (Applied Biosystems, Foster City, CA) in an Applied Biosystems 3730 XL DNA Analyzer (Applied Biosystems) by the Genomic Sciences Laboratory (North Carolina State University, Raleigh).

DNA sequencing and phylogenetic analyses. DNA sequences were edited with ChromasPro1.5 2003-2009 (Technelysium Pty. Ltd., Helensvale, Australia) and aligned using ClustalW (http:// workbench.sdsc.edu; Bioinformatics and Computational Biology group, Department of Bioengineering, University of California, San Diego). The sequences obtained in this study were deposited into the GenBank database under the accessions numbers listed in Table 1. Outgroup species and other species from GenBank were also used for phylogenetic analysis. In order to reduce the ambiguous sites and include more species in multiple DNA sequence alignments in one dataset, phylogenetic analysis using Bayesian inference of the populations was divided into the five groups: Tylenchids, Criconematids, Longidorids, Xiphinematids, and Trichodorids. The models of base substitution in the $18 \mathrm{~S}$ sequence data were evaluated using MODELTEST version 3.06 (Posada and Criandall 1998). ITS1 is highly variable across genera and is not suited for phylogenetic analysis above the genus level. Thus, ITS1 sequence data were used for specific confirmation only, not for constructing phylogenetic relationships. The Akaike-supported model (Arnold 2010), the proportion of invariable sites, and the $\gamma$ distribution shape parameters and substitution rates were used in phylogenetic analyses using $18 \mathrm{~S}$ sequence data. Bayesian analysis was performed to confirm the tree topology for each gene separately using MrBayes 3.1.0 (Huelsenbeck and Ronquist 2001), running the chain for 1,000,000 generations and setting the burn-in at 1,000. Markov Chain Monte Carlo methods were used within a Bayesian framework to estimate the posterior probabilities (pp) of the phylogenetic trees (Larget and Simon 1999) using the $50 \%$ majority rule. The $\lambda 2$ test for homogeneity of base frequencies and phylogenetic trees was performed using PAUP* (version 4.0; Sinauer Associates, Inc. Publishers, Sunderland, MA).

\section{Results}

Near-full-length 18S rDNA (60 populations, including ITS1) sequences from 65 plant-parasitic nematodes were obtained in this study (Table 1). These nematode populations from turfgrass in North Carolina and South Carolina belonged to 28 species from 13 families (Zeng et al. 2012b). Phylogenetic analysis of the $18 \mathrm{~S}$ sequence included $67,48,27,42$, and 24 nematode populations within the groups Tylenchid, Criconematid, Longidorid, Xiphinematid, and Trichodorid, respectively. The proportion of constant characters of these datasets was $62,71,91,85$, and $81 \%$, respectively. The $\lambda^{2}$ test showed that homogeneity of base frequencies across taxa was not rejected for any of the datasets. The trees produced by Bayesian analysis of $18 \mathrm{~S}$ sequence data are presented in Figures 1 through 5.

Eleven nematode species within the Tylenchid group (Table 1; B. longicaudatus, Cactodera sp., D. heterocephalus, Helicotylenchus dihystera, Heterodera sp., Hoplolaimus galeatus, M. graminis, M. naasi, Pratylenchus penetrans, Scutellonema brachyurum, and Tylenchorynchus claytoni) were found during the survey (Zeng et al. $2012 b$ ). The blastn search of 31 of these populations matched well with data of corresponding species found in GenBank.

Three B. longicaudatus populations (T5, T10, and T63) from turfgrass were analyzed in this study. The sequences of the near-fulllength 18S plus ITS1 sequence from these three populations had 2,239 identical nucleotides (identity $=2,239 / 2,242=99 \%$ ). The blastn search of the $18 \mathrm{~S}$ sequence of three $B$. longicaudatus populations (DQ912919, AY633449, and EU130838) in GenBank revealed high similarity ( $99 \%$ identities) with the three populations found in this study. When the ITS 1 sequence was considered for these same $B$. longicaudatus populations, they shared 464 to $466(99 \%)$ identical nucleotides with four populations of $B$. longicaudatus (GQ896549, DQ494792, DQ672369, and DQ672368) in GenBank. 
Two Cactodera sp. populations (T42 and 12-33402) were analyzed in this study. The $18 \mathrm{~S}$ sequences of these populations shared 624 identical nucleotides (100\%). The $18 \mathrm{~S}$ sequence alignment of T42, 12-33402, and Cactodera sp. (AY911929) in GenBank yielded 624 total characters with 623 identical nucleotides (99\%).

One population of $D$. heterocephalus (T76) and one population of Helicotylenchus dihystera (T35) were analyzed. The blastn search of the $18 \mathrm{~S}$ sequence of $D$. heterocephalus (T76) revealed the highest match with Dolichodorus sp. (EF025336). Alignment of these two sequences yielded 1,723 identical nucleotides (100\%). From the $18 \mathrm{~S}$ sequence alone, the $H$. dihystera population from this study (T35) was identical to H. dihystera (AJ966486) in GenBank (1,763/ $1,763=100 \%$ ).

An unidentified population of Heterodera sp. (T75) was found (Zeng et al. 2012b). Alignment of partial 18S plus ITS1 sequences from T75 and two other species-H. mani (EU669916) and H. avenae (FJ040403) - in GenBank yielded 1,477 total characters with 1,472 and 1,470 identical nucleotides (99\%).

Four populations of Hoplolaimus galeatus (T2, T29, T62, and T65) were analyzed in this study. The $18 \mathrm{~S}$ plus ITS1 sequences from these populations had 2,308 identical nucleotides $(2,308 / 2,308=$ $100 \%)$. The blastn search of the ITS1 sequence of these four populations was similar to H. galeatus (EU515321 and EU515322) in GenBank. Alignment of these six sequences yielded 529 total characters with 528 identical nucleotides (100\%). Two populations of H. columbus, one from cotton (11-16545) and other from soybean (12-22307), were used for comparison. The $18 \mathrm{~S}$ sequences $(1,587 \mathrm{bp})$ of these two populations and the four turfgrass populations of $H$. galeatus shared $95 \%$ identities.
The 18S plus ITS1 sequences of five populations of $M$. graminis (T44, T54, T56, T60, and T61) had 1,891 identical nucleotides $(1891 / 1950=97 \%)$. The blastn search of the $18 \mathrm{~S}$ sequence had a high match with M. graminis (JN241838), with 99\% identity. Three populations of $M$. naasi were sequenced (T51, T53, and T74), with the $18 \mathrm{~S}$ plus ITS 1 sequences $(2,015 \mathrm{bp})$ among these populations having 0 to 5 nucleotide differences. The blastn search of the $18 \mathrm{~S}$ sequence matched those of M. naasi (AY593900 and AY593901). Sequence alignment of these five populations yielded 1,687 total characters (99\%), with 0 to 5 nucleotide differences and four insertions or deletions. Three $M$. nassi populations from this study (T51, T53, and T74) had 322 identical nucleotides $(322 / 322=100 \%)$ and one insertion or deletion $(0 \%)$ in the ITS1 region. These populations shared 322 identical nucleotides with two other populations of $M$. naasi (EU910042 and EU910045).

P. penetrans (T6), S. brachyurum (T58), and T. claytoni (T11 and T38) were found in the survey. The $18 \mathrm{~S}$ sequence alignment of $P$. penetrans T6 with $P$. penetrans (EU669925) was 99\% identical. Alignments of the 18S plus ITS1 sequences showed 99\% identities between $S$. brachyurum (T58) and S. brachyurum (DQ316097) and between populations of T. claytoni (T11 and T38) and T. claytoni (EU368587).

Phylogenetic analysis inferred from the $18 \mathrm{~S}$ sequences revealed four distinct clades of tylenchid species recovered from turfgrass and other crops (Fig. 1). Clade I ( $\mathrm{pp}=100 \%$ ) comprised nematodes in the families Hoplolaimidae and Heteroderidae and had 30 populations, including 14 from the current study: Helicotylenchus dihystera (T35), S. brachyurum (T58), Cactodera sp. (T41, T42, and 12-33402), Heterodera sp. (T75), Heterodera glycines (T70

Table 1. Details of plant-parasitic nematode populations from a survey of turfgrass and other hosts in North Carolina and South Carolina included in phylogenetic study

\begin{tabular}{|c|c|c|c|c|}
\hline Genera, species & Host $^{\mathbf{a}}$ & Locality (county, state) & Isolate code (DNA \& lab ID) & Accession number ${ }^{\mathbf{b}}$ \\
\hline \multicolumn{5}{|l|}{ Tylenchid } \\
\hline Belonolaimus longicaudatus & Bermudagrass & Lenoir, NC & T5 11-2030 & KJ934129 \\
\hline B. longicaudatus & Turfgrass & Moore, NC & T10 11-3366 & KJ934128 \\
\hline B. longicaudatus & Bermudagrass & Beaufort, SC & T63 11-30676 & KJ934136 \\
\hline B. longicaudatus & Peach & Montgomery, NC & $11-29875$ & KJ934139 \\
\hline B. longicaudatus & Tobacco & Sampson, NC & $12-25409$ & KJ934140 \\
\hline Cactodera sp. & Turfgrass & Cumberland, NC & T42 11-30146 & KJ934135 \\
\hline Cactodera sp. & Turfgrass & Cumberland, NC & $12-33402$ & KJ934187 \\
\hline Cactodera sp. & Watermelon & Sampson, NC & T41 10-27762 & KJ934145 \\
\hline Dolichodorus heterocephalus & Turfgrass & New Hanover, NC & T76 12-675 & KJ934144 \\
\hline Helicotylenchus dihystera & Turfgrass & Wake, NC & T35 11-29935 & KJ934127 \\
\hline Heterodera glycines & Soybean & Gates, NC & T70 11-30739 & KJ934138 \\
\hline H. glycines & Soybean & Gates, NC & T70b 11-30739 & KJ934142 \\
\hline Heterodera $\mathrm{sp}$. & Bermudagrass & Horry, SC & T75 11-30748 & KJ934134 \\
\hline Hoplolaimus columbus & Cotton & Scotland, NC & $11-16545$ & KJ934149 \\
\hline H. columbus & Soybean & Edgecombe, NC & $12-22307$ & KJ934150 \\
\hline H. galeatus & Centipede grass & Cumberland, NC & T2 11-1848 & KJ934131 \\
\hline H. galeatus & Bermudagrass & Beaufort, SC & T65 11-30676 & KJ934146 \\
\hline H. galeatus & Bermudagrass & Beaufort, SC & T62 11-30688 & KJ934147 \\
\hline H. galeatus & Turfgrass & New Hanover, NC & T29 11-29594 & KJ934148 \\
\hline Meloidogyne graminis & Bermudagrass & Kershaw, SC & T44 11-30365 & KJ934143 \\
\hline M. graminis & Bentgrass & Avery, NC & T54 11-30385 & KJ934153 \\
\hline M. graminis & Bermudagrass & Burke, NC & T56 11-30389 & KJ934154 \\
\hline M. graminis & Bermudagrass & Beaufort, SC & T60 11-30673 & KJ934152 \\
\hline M. graminis & Bermudagrass & Beaufort, SC & T61 11-30688 & KJ934155 \\
\hline M. naasi & Bentgrass & Avery, NC & T51 11-30383 & KJ934133 \\
\hline M. naasi & Bentgrass & Avery, NC & T53 11-30385 & KJ934132 \\
\hline M. naasi & Turfgrass & Greenville, SC & T74 12-44 & KJ934151 \\
\hline Pratylenchus penetrans & Bermudagrass & Craven, $\mathrm{NC}$ & T6 11-2088 & KJ934156 \\
\hline Scutellonema brachyurum & Turfgrass & New Hanover, NC & T58 $11-29736$ & KJ934137 \\
\hline Tylenchorhynchus claytoni & Turfgrass & Moore, NC & T11 11-3366 & KJ934130 \\
\hline T. claytoni & Turfgrass & New Hanover, NC & Т38 11-29736 & KJ934141 \\
\hline
\end{tabular}

\footnotetext{
a When the specific turfgrass species was not known, 'Turfgrass' was used as the host designation.

b Accession numbers under which deposited in GenBank. Deposited sequences were from 18S and internal transcribed spacer ribosomal DNA.

c Sequences deposited in GenBank only included 18S sequence data.
} 
and T70b from soybean), Hoplolaimus galeatus (T2, T29, T62, and T65), and H. columbus (11-16545 and 12-22307). Within this clade, six Hoplolaimus populations were in a highly supported $(\mathrm{pp}=100 \%)$ monophyletic clade and sister to two populations of Rotylenchus (AJ966503 and EU306356), also with high support (pp =99\%). Heterodera sp. (T75) and Heterodera glycines (T70 and T70b) were in a highly supported $(\mathrm{pp}=100 \%)$ monophyletic clade with six other Heterodera populations. Three other Heteroderidae populations (Cactodera sp. T41, T42, and 12-33402) appeared close to a clade consisting of five Helicotylenchus populations (T35, AJ966486, FJ969124, AY284606, and T58); however, this clade was weakly supported $(\mathrm{pp}<50 \%)$.

Clade II ( $\mathrm{pp}=100 \%$ ), belonging to the family Belonolaimidae, contained eight populations, including the five turfgrass populations of Belonolaimus (T5, T10, T63, 11-29875, and 12-25409; Fig. 1). All sequenced Belonolaimus populations were within a monophyletic clade with $100 \%$ support. Clade III ( $\mathrm{pp}=55 \%)$ consisted of 27 populations belonging to four families: Meloidogynidae, Tylenchidae, Pratylenchidae, and Telotylenchidae. All 15 Meloidogyne populations, including $M$. naasi (T51, T53, and T74) and M. graminis (T44, T60, T54, T56, and T61), were all within a highly supported $(\mathrm{pp}=100 \%)$ monophyletic clade and sister to a clade with three populations of Pratylenchidae (FJ969136, KJ934156, and AF442189), including $P$. penetrans (T6), with $98 \%$ support. This population was also in a highly supported clade $(\mathrm{pp}=100 \%)$ with $P$. convallariae (FJ969136). The clade containing Meloidogyne and Pratylenchus spp. was sister to Zygotylenchus (AF442189). Five populations of
Telotylenchidae, including T. claytoni (T11 and T38, both from turfgrass) as well as T. claytoni (EU368587, AY993979, and AY593905), were grouped in a moderately $(\mathrm{pp}=79 \%)$ supported clade but in a weakly supported $(\mathrm{pp}=67 \%)$ clade with Hirschmanniella loofi (EU306353). Two turfgrass populations of T. claytoni (T11 and T38) and another population of T. claytoni (EU368587) were in a clade with $100 \%$ support. Clade IV ( $\mathrm{pp}=100 \%$ ) included two populations of Dolichodoridae. The turfgrass population D. heterocephalus (T76) was identical to an unidentified Dolichodorus sp. (EF025336) in GenBank.

Eleven nematode species, including Hemicaloosia graminis, Hemicriconemoides wessoni, Hemicycliophora wyei, H. thienemanni, Hemicycliophora sp., Mesocriconema sp., Mesocriconema sphaerocephalum, M. xenoplax, and Paratylenchus goldeni, were found during this survey (Zeng et al. 2012b). The blastn search of 26 populations from the current study matched well with data of corresponding species found in GenBank. Two populations of Hemicaloosia graminis (T14 and T77) were analyzed in this study. The $18 \mathrm{~S}$ plus ITS1 sequence alignment of these populations yielded 1,961 total characters with 1,953 identical nucleotides (99\%) and one insertion or deletion $(0 \%)$. The $18 \mathrm{~S}$ blastn search of these two populations revealed the highest match as $H$. vagisclera (JQ246426). Alignment of these three sequences yielded 1,495 total characters with 1- to 2-bp differences.

The 18S plus ITS1 sequences of four Hemicriconemoides wessoni populations (T12, T49, T59, and 09-24185) shared 1,182 identical nucleotides (98 to $99 \%$ ). From the $18 \mathrm{~S}$ sequence alone (only partial

Table 1. (continued from preceding page)

\begin{tabular}{|c|c|c|c|c|}
\hline Genera, species & Host $^{\mathbf{a}}$ & Locality (county, state) & Isolate code (DNA \& lab ID) & Accession number ${ }^{b}$ \\
\hline \multicolumn{5}{|l|}{ Criconematid } \\
\hline Hemicaloosia graminis & Turfgrass & New Hanover, NC & T77 10-27720 & JQ446376 \\
\hline H. graminis & Centipede grass & New Hanover, NC & T14 11-3379 & KJ934167 \\
\hline Hemicriconemoides chitwoodi & Boxwood & Cumberland, NC & T32 11-29905 & KJ934162 \\
\hline H. wessoni & Bermudagrass & Brunswick, NC & $09-24185$ & KJ934163 \\
\hline H. wessoni & Centipede grass & New Hanover, NC & T12 11-3379 & KJ934164 \\
\hline H. wessoni & Bermudagrass & Kershaw, SC & T49 11-30365 & KJ934165 \\
\hline H. wessoni & Bermudagrass & Beaufort, SC & T59 11-30664 & KJ934166 \\
\hline Hemicycliophora wyei & Turfgrass & New Hanover, NC & T39 11-29736 & KJ934172 \\
\hline H. wyei & Turfgrass & New Hanover, NC & T46 11-30321 & KJ934173 \\
\hline H. wyei & Turfgrass & New Hanover, NC & T57 11-30316 & KJ934174 \\
\hline Hemicycliophora sp. & Bermudagrass & New Hanover, NC & T15 11-3357 & KJ934170 \\
\hline Hemicycliophora sp. & Turfgrass & New Hanover, NC & T28 11-29594 & KJ934169 \\
\hline H. thienemanni & Bermudagrass & Charleston, SC & T72 11-30769 & KJ934168 \\
\hline H. thienemanni & Corn & Greene, NC & M62 08-4103 & KJ934171 ${ }^{\mathrm{c}}$ \\
\hline Mesocriconema sphaerocephalum & Bermudagrass & Beaufort, SC & T64 11-30664 & KJ934182c \\
\hline M. xenoplax & Turfgrass & Wallace, NC & T3 $11-1978$ & KJ934176 \\
\hline M. xenoplax & Turfgrass & Wake, NC & T34 11-29935 & KJ934177 \\
\hline M. xenoplax & Bermudagrass & Nash, NC & T37 11-29404 & KJ934178 \\
\hline M. xenoplax & Turfgrass & Greenville, SC & T73 12-44 & KJ934180 \\
\hline M. xenoplax & Peach & Montgomery, $\mathrm{NC}$ & T33 11-29849 & KJ934179c \\
\hline Mesocriconema sp. & Centipede grass & New Hanover, NC & T13 11-3379 & KJ934185 \\
\hline Mesocriconema sp. & Centipede grass & New Hanover, NC & T27 11-29593 & KJ934184c \\
\hline Mesocriconema sp. & Bermudagrass & Dare, NC & T8 11-2734 & KJ934181 \\
\hline Ogma sp. & Boxwood & Columbus, NC & $12-23998$ & KJ934161 \\
\hline Ogma sp. & Daylily & Brunswick, NC & $13-9959$ & KJ934175 \\
\hline Paratylenchus goldeni & Centipede grass & Cumberland, $\mathrm{NC}$ & Т36 11-29913 & KJ934186 \\
\hline \multicolumn{5}{|l|}{ Longidorid } \\
\hline Longidorus paralongicaudatus & Turfgrass & Brunswick, NC & $12-24191$ & KJ934123 \\
\hline \multicolumn{5}{|l|}{ Xiphinematid } \\
\hline Xiphinema americanum & Turfgrass & Moore, NC & Т30 11-29987 & KJ934159 \\
\hline$X$. americanum & Turfgrass & New Hanover, NC & T40 11-29736 & KJ934158 \\
\hline$X$. chambersi & Zoysiagrass & New Hanover, NC & T4 11-1995 & KJ934157 \\
\hline X. chambersi & Daylily & Robeson, NC & $10-23191$ & KJ934160 \\
\hline \multicolumn{5}{|l|}{ Trichodorid } \\
\hline Paratrichodorus allius & Bentgrass & Avery, NC & T52 11-30383 & KJ934124 \\
\hline Nanidorus minor & Bermudagrass & Kershaw, SC & T43 11-30365 & KJ934125 \\
\hline N. minor & Bermudagrass & Rio Grande, Puerto Rico & T20 11-6013 & KJ934126 \\
\hline
\end{tabular}


for T12 and T49), alignment of these four populations with $H$. wessoni (JF972467) in GenBank revealed 99 to $100 \%$ identities.

Six turfgrass populations of Hemicycliophora were analyzed in this study, including three populations of Hemicycliophora wyei (T39, T46, and T57), one population of H. thienemanni (T72), and two unidentified populations of Hemicycliophora (T15 and T28). The 18S plus ITS1 sequences (partial 18S for T57) from of the three populations of $H$. wyei (T39, T46, and T57) shared 1,169 identical nucleotides (98 to 99\%). The ITS1 blastn search of the same three populations were identical $(560 / 560=100 \%)$ to $H$. wyei $(\mathrm{KF} 430528)$ from GenBank. The $18 \mathrm{~S}$ blastn search of $H$. thienemanni (T72) revealed the highest match (99\%) with H. thienemanni (EU306341).

Nine populations of Mesocriconema were analyzed in this study, including M. sphaerocephalum (T64), M. xenoplax (T3, T33, T34, T37, and T73), and three unidentified populations of Mesocriconema (T8, T13, and T27). A blastn search showed that no $18 \mathrm{~S}$ sequence of $M$. sphaerocephalum was available for comparison in GenBank. M. sphaerocephalum $(\mathrm{T} 64)$ had 1,631 $(1,631 / 1,710=95 \%)$ and $1,529(1,529 / 1,603=95 \%)$ identical nucleotides with M. xenoplax (AY284625 and AY284626). Alignment of the $18 \mathrm{~S}$ sequences from M. xenoplax (T3, T33, T34, T37, and T73) with one population of M. xenoplax (AY284625) from GenBank revealed 99\% identities.

One population of $P$. goldeni (T36) was recovered during the survey (Zeng et al. 2012b). No sequence data for $P$. goldeni were available for comparison in GenBank. The $18 \mathrm{~S}$ sequence shared 1,543 to 1,671 identical nucleotides (96 to 98\%) with Paratylenchus spp. (AJ966496, AY284630, AY284633, and AY284634).

Phylogenetic analysis inferred from the $18 \mathrm{~S}$ sequence revealed six distinct clades of Ccriconematid species (Fig. 2). In total, six major clades (five highly and one weakly supported) were identified within this group. Clade I ( $\mathrm{pp}=57 \%)$ consisted of 14 populations, including six from the present study: Ogma sp. (12-23998) and Hemicriconemoides chitwoodi (T32) from boxwood, and four populations of Hemicriconemoides wessoni (T12, T49, T59, and 09-24185) from turfgrass. Within this clade, relationships between the genera Hemicriconemoides, Ogma, Criconema, and Crossonema, were unresolved. Two populations of Ogma (13-9959 from boxwood and 12-23998 from daylily) were not identified to species level due to lack of sufficient specimens. Bayesian analysis based on the $18 \mathrm{~S}$ sequence showed that these two populations were clustered in two distinct clades. Ogma sp. (13-9959) was in a highly supported (pp = 100\%) clade (clade IV; Fig. 2) with Ogma serratum (HM116031), which was in a highly supported $(\mathrm{pp}=100 \%$ ) clade with the genus Hemicycliophora. Ogma sp. (12-23998) was in a highly supported ( $\mathrm{pp}=100 \%)$ clade with Crossonema sp. (FJ969120) in clade I (Fig. 2), with species in the genera Criconema, Crossonema, and Hemicriconemoides, indicating that the genus Ogma included six selected populations appearing to be paraphyletic. Clade II (pp = $100 \%$ ) included Caloosia longicaudata (GU989624), Hemicaloosia graminis (T14and T77), and H. vagisclera (JQ246426). C. longicaudata formed a highly supported clade $(\mathrm{pp}=100 \%)$ with three populations of Hemicaloosia as a sister taxon. Clade III $(\mathrm{pp}=100 \%)$ consisted of 12 populations, including 7 populations from this survey: Hemicycliophora thienemanni (T72 and M62), Hemicycliophora sp. (T15), Hemicycliophora sp. (T28), and H. wyei (T39,
T46, and T57). Twelve populations of Hemicycliophora were in a highly supported $(\mathrm{pp}=100 \%)$ monophyletic clade. Five populations of $H$. thienemanni (T72, M62, EU306341, AY284628, and AY284629) formed a highly supported clade ( $\mathrm{pp}=98 \%)$ with two unidentified Hemicycliophora populations (T15 and T28). H. wyei was associated with $H$. conida (AJ966471), with moderate support $(\mathrm{pp}=82 \%)$. The highly supported $(\mathrm{pp}=100 \%)$ clade IV consisted of two populations of Ogma, including the study population 13-9959 from daylily. Clade V $(\mathrm{pp}=100 \%)$ included nine populations of Mesocriconema from turfgrass and three other populations of $M$. xenoplax from GenBank in a highly supported $(\mathrm{pp}=100 \%)$ monophyletic clade. Six of our $M$. xenoplax populations, three M. xenoplax from GenBank, and one population of $M$. sphaerocephalum (T64) were in a highly supported $(\mathrm{pp}=100 \%)$ clade and were sister taxa of two unidentified populations of Mesocriconema (T13 and T27). Clade VI ( $\mathrm{pp}=100 \%$ ) contained five populations of Paratylenchus, including one from turfgrass (P. goldeni; T36).

There was one population of a Longidorid recovered during our survey (Zeng et al. 2012b). The blastn search of the near-fulllength $18 \mathrm{~S}$ sequence of this population (12-24191) revealed the highest match as Longidorus paralongicaudatus (AY283160), with 99\% identity. Based on Bayesian analysis, L. paralongicaudatus (12-24191) is in a strongly supported clade ( $\mathrm{pp}=100 \%$ ) with L. paralongicaudatus (AY283160) from hickory in Washington, AR (Fig. 3). This clade was in a well-supported $(100 \%)$ monophyletic clade with five other species in the genus Longidorus from different hosts in the United States. The study population was sister to L. biformis (AY283171) and L. americanus (AY283168).

Two Xiphinematid nematode species, Xiphinema americanum and $X$. chambersi, were detected during our survey (Zeng et al. $2012 \mathrm{~b}$ ). Two populations of $X$. americanum from turfgrass (T30 and T40) and two populations of $X$. chambersi from turfgrass (T4) and daylily (10-23191) were analyzed. A blastn search of these four populations matched with their corresponding species. From the $18 \mathrm{~S}$ sequence alone, the two populations of $X$. chambersi (T4 and 10-23191) and X. chambersi (AY283174) in GenBank yielded 1,739 total characters with $99 \%$ identities. One survey population, $X$. americanum $(\mathrm{T} 30)$, shared 1,752 $(1,752 / 1,753=99 \%)$ identical nucleotides with $X$. americanum (AM086672), 1,761 (1,761/ $1,763=99 \%$ ) with $X$. americanum (AM086684), and 1,757 $(1,757 / 1,762=99 \%)$ with $X$. americanum (AY283170). The other survey population, $X$. americanum (T40), shared 1,750 (1,750/ $1,752=99 \%$ ) with $X$. americanum (AM086672), 1,759 (1,759/ $1,762=99 \%$ ) with $X$. americanum (AM086684), and 1,755 $(1,755 / 1,761=99 \%)$ identical nucleotides with $X$. americanum (AY283170). However, both T30 and T40 shared 98\% identical nucleotides with a Portugal population of $X$. americanum $(\mathrm{AM} 086679 ; 1,717 / 1,754=98 \%$ for T30 , and $1,715 / 1,753=98 \%$ for T40). T30 shared $99 \%$ identical nucleotides with T40 $(1,767 /$ $1,768=99 \%$ ).

Phylogenetic analysis inferred from the $18 \mathrm{~S}$ sequence revealed two distinct clades of Xiphinema spp., representing X. americanumgroup and non- $X$. americanum-group nematodes (Fig. 4). $X$. chambersi (T4) and X. chambersi (10-23191) were grouped into one clade (non$X$. americanum-group) and two study populations of $X$. americanum

Table 2. Primers used for polymerase chain reaction and DNA sequencing of plant-parasitic nematodes recovered during a survey of turfgrass in North Carolina and South Carolina ${ }^{\mathrm{a}}$

\begin{tabular}{llll}
\hline Primer & Marker & \multicolumn{1}{c}{ Sequence $\left(\mathbf{5}^{\prime}\right.$ to $\mathbf{3}^{\prime}$ ) } & Reference \\
\hline SSUF07 & $18 \mathrm{~S}$ & AAAGATTAAGCCATGCATG & Floyd et al. (2002) \\
SSUR26 & $18 \mathrm{~S}$ & CATTCTTGGCAAATGCTTTCG & Floyd et al. (2002) \\
18 S965 & $18 \mathrm{~S}$ & GGCGATCAGATACCGCCCTAGTT & Mullin et al. (2005) \\
18 S1573R & $18 \mathrm{~S}$ & TACAAAGGGCAGGGACGTAAT & Mullin et al. (2005) \\
18 SnF & $18 \mathrm{~S}$ & TGGATAACTGTGGTAATTCTAGAGC & Kanzaki and Futai (2002) \\
18 SnR & $18 \mathrm{~S}$ & TTACGACTTTTGCCC GGTTC & Kanzaki and Futai (2002) \\
rDNA2 & ITS1 & TTGATTACGTTCCCTGCCCTTT & Vrain et al. (1992) \\
rDNA1.58S & ITS1 & ACGAGCCGAGTGATCCACCG & Cherry et al. (1997) \\
\hline
\end{tabular}

a rDNA = ribosomal DNA and ITS = internal transcribed spacer. 
(T30 and T40) were clustered within another clade (X. americanum group). The two $X$. chambersi populations (T4 and 10-23191) were in a strongly supported (100\%) monophyletic clade with $X$. chambersi (AY283174) from maple (Lawrence, AR). This species is closer to $X$. turcicum (GU725086), X. paritaliae (AY297831), and X. ifacolum (AY297826) than other species in the non-X. americanum-group. The $2 X$. americanum populations in this study (T30 and T40) were in a highly supported (100\%) monophyletic clade with 12 other Xiphinema populations, including $3 X$. americanum (AY283170, AM086672, and AM086684), $X$. floridae (AM086687), and X. georgianum (AM086688) from the United States; X. cf. americanum (AM086679) from Portugal; X. brevicolle (AY297822) and X. oxycaudatum (AY297835) from

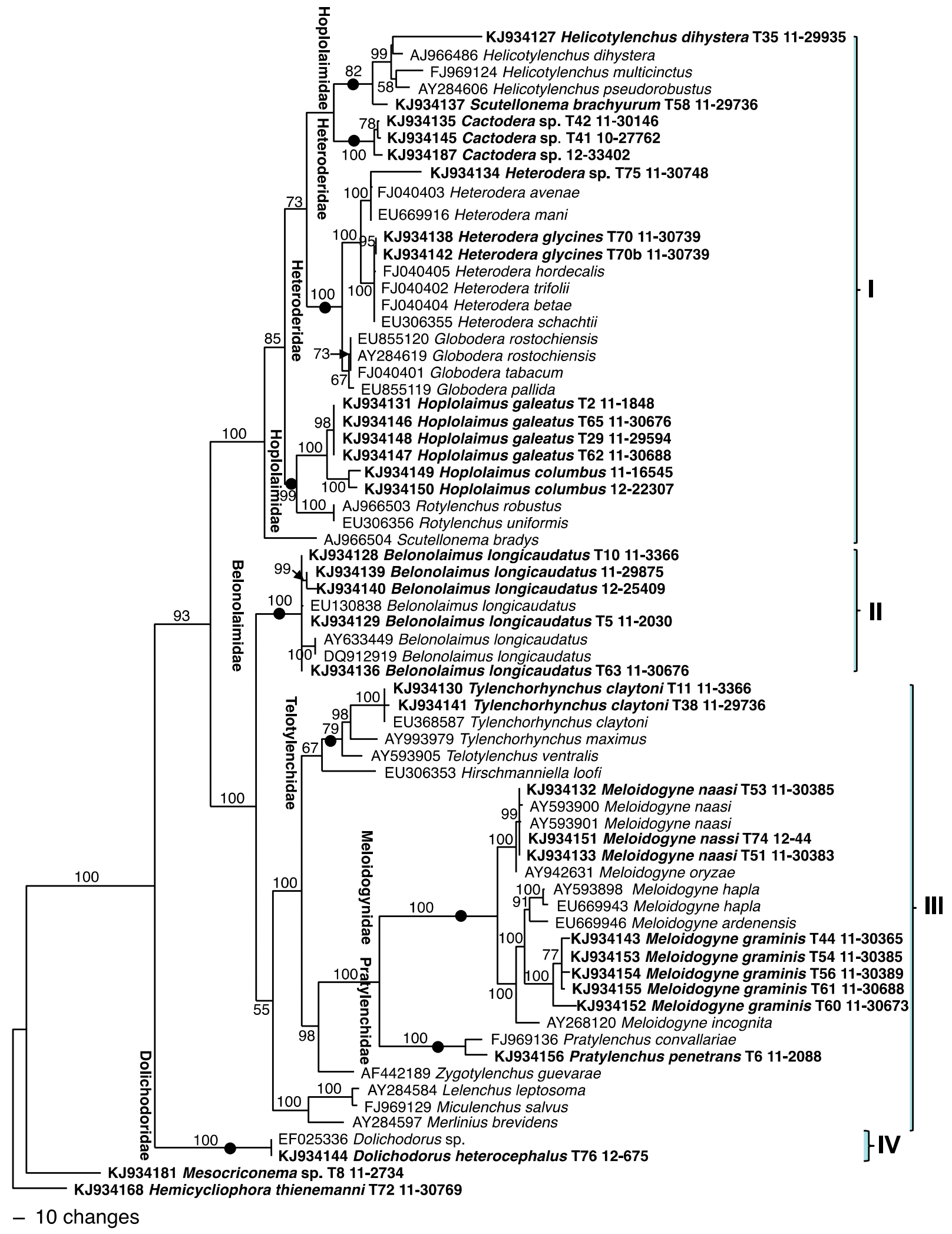

Fig. 1. Phylogenetic relationships among 18 genera and 67 species of Tylenchid nematodes collected from turfgrass sites in North Carolina and South Carolina inferred from the 10,001 replicate of Bayesian analysis deduced from 18S rDNA sequences. Two Criconematid species sequences are outgroups. Numbers at nodes indicate bootstrap scores $>50 \%$. The phylogenetic tree was generated using MrBayes 3.1.0 (Huelsenbeck and Ronquist 2001). 
Brazil; X. diffusum (AM086685) from Australia; X. incognitum (AM086670) from China; X. simile (AM086681) from Serbia; and $X$. taylori (AM086675) from Slovakia. Both study populations were closer in relationship to the three U.S. populations (AY283170, AM086672, and AM086684) of X. americanum than to the $X$. cf. americanum from Portugal (AM086679).
Two Trichodorid nematode species, Paratrichodorus allius and Nanidorus minor, were recovered during our survey (Zeng et al. 2012b). The blastn search of three turfgrass trichodorid populations (T20, T43, and T52) matched with their corresponding species. Alignment of $18 \mathrm{~S}$ and ITS1 sequences from the survey population $P$. allius (T52) and P. allius (AM087124) in GenBank yielded

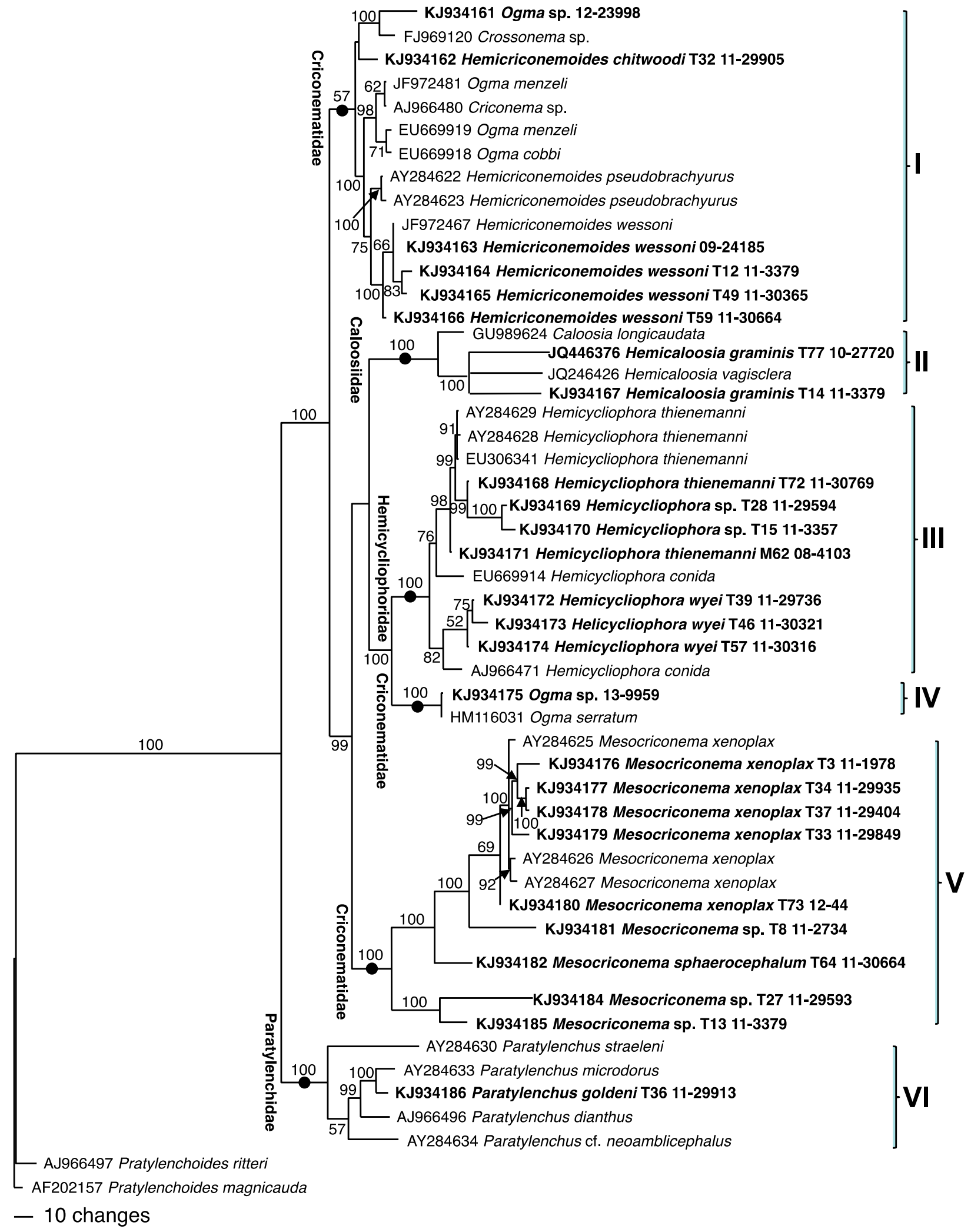

Fig. 2. Phylogenetic relationships among nine genera and 49 species of Criconematid nematodes collected from turfgrass sites in North Carolina and South Carolina inferred from the 10,001 replicate of Bayesian analysis deduced from 18S rDNA sequences. Two Pratylenchoides spp. sequences are outgroups. Numbers at nodes indicate bootstrap scores $>50 \%$. The phylogenetic tree was generated using MrBayes 3.1.0 (Huelsenbeck and Ronquist 2001). 
2,280 total characters with 2,258 identical nucleotides (99\%) and seven insertions or deletions (0\%). From the $18 \mathrm{~S}$ sequence alone, the survey population $P$. allius $($ T52) shared 1,731 (1,731/1,736= $99 \%$ ) identical nucleotides with $P$. allius (AM269895) and 1,717 $(1,717 / 1,724=99 \%)$ with $P$. allius (AJ439572). Using ITS1 sequence data, the survey population $P$. allius (T52) shared 540 $(540 / 546=99 \%)$ identical nucleotides with P. allius (AM087124). The $18 \mathrm{~S}$ sequences of two populations of $N$. minor (T20 and T43) had 1,685 identical nucleotides $(1,685 / 1,696=99 \%)$ and three insertions or deletions $(3 / 1,696=0 \%)$. The $18 \mathrm{~S}$ sequences from the survey population $N$. minor (T20) shared $1,725(1,725 /$ $1,734=99 \%)$ and $1,659(1,659 / 1,664=99 \%)$ identical nucleotides with $N$. minor (AM269897) and $N$. minor (DQ345526), respectively. The $18 \mathrm{~S}$ sequences from another survey population of $N$. minor (T43) shared 1,689 $(1,689 / 1,703=99 \%)$ identical nucleotides with $N$. minor (AM269897) and 1,654 $(1,654 / 1,664=99 \%)$ with N. minor (DQ345526).

Phylogenetic analysis inferred from the $18 \mathrm{~S}$ sequence revealed two distinct clades of Trichodorid (Fig. 5). P. allius (T52) and N. minor (T20 and T43) were in two different clades. P. allius (T52) was in a highly supported (97\%) monophyletic clade with three U.S. $P$. allius populations (AJ439572, AM087124, and AM269895). This clade was sister to three populations of $P$. teres (AJ439575, AM087125, and AM269896). One $P$. allius population (AJ439623) from Utah was in a basal position in this clade. Two survey populations of $N$. minor (T20 and T43) were in a highly supported (100\%) monophyletic clade with populations of $N$. minor from Greece (AM269897) and from
Portugal (DQ345526). This species appeared to be sister to P. porosus, with $100 \%$ support.

\section{Discussion}

Previous studies revealed intraspecific variability in the $18 \mathrm{~S}$ and 28S D2/D3 rDNA as well as the mtDNA in nematodes (Kumari and Subbotin 2012; Lazarova et al. 2006; Neilson et al. 2004; Oliveira et al. 2004). In the present study, there were minor DNA sequence differences within the detected plant-parasitic nematode populations. However, morphological examination of the populations matched well with the original or previous descriptions. Thus, these minor DNA sequence differences were considered to be intraspecies variation. These results are similar to intraspecific divergence reported for other nematodes such as $L$. diadecturus (Neilson et al. 2004), the $X$. setariae/vulgare complex (Oliveira et al. 2004), and $X$. americanum-group populations from North America (Lazarova et al. 2006). This study included 13 sequences of plant-parasitic nematode populations from other plant hosts to compare with nematode sequences from turfgrasses; no significant sequence differences was observed for these species from different hosts.

There are thousands of $18 \mathrm{~S}$ nematode sequences in the GenBank database, providing an extensive and growing resource for comparison (Griffiths et al. 2006). The 18S rDNA sequences have been used extensively in phylogenetic studies (Bert et al. 2008; Blaxter et al. 1998; Gutiérrez-Gutiérrez et al. 2010, 2012, 2013; Kumari and Subbotin 2012; Oliveira et al. 2004; Subbotin et al. 2008; Ye et al. 2007). However, the vast majority of nematode species have not been

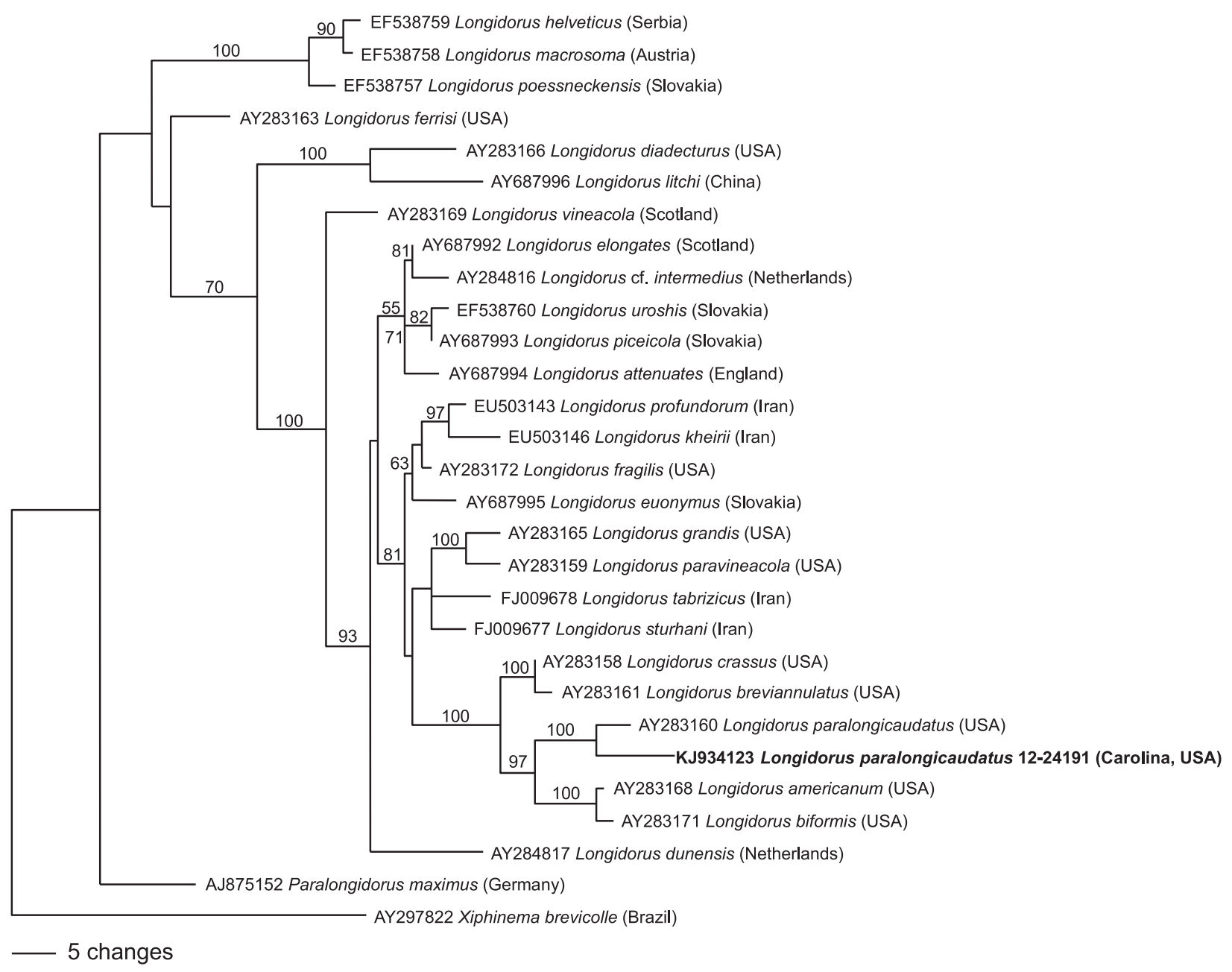

Fig. 3. Phylogenetic relationships among two genera and 28 species of Longidorid nematodes collected from turfgrass sites in North Carolina and South Carolina inferred from the 10,001 replicate of Bayesian analysis deduced from 18S rDNA sequences. A Xiphinema sp. sequence is an outgroup. Numbers at nodes indicate bootstrap scores $>50 \%$. The phylogenetic tree was generated using MrBayes 3.1.0 (Huelsenbeck and Ronquist 2001). 
sequenced. For example, M. sphaerocephalum (T64) and Paratylenchus goldeni (T36) were sequenced in this study but sequences for these nematodes were not available in GenBank. Molecular identification of nematodes is still a challenge due to the degree of sequence conservation and the availability of deposited $18 \mathrm{~S}$ sequences for comparison. In the present study, several cyst or cystoid nematode populations were not identified to the species level, mainly because very limited sequences of Cactodera were available in GenBank. In our survey (Zeng et al. $2012 \mathrm{~b}$ ), only the second-stage juveniles of these genera were observed in soil samples, and no adult females or cysts were recovered for species identification. Five criconematid populations were also found during the survey; however, they were not identified to species level because of lack of sufficient specimens for morphological identification and no identical matches in GenBank. Within some nematode genera, such as Heterodera, the $18 \mathrm{~S}$ gene sequence is highly conserved among different species. The sequences are nearly identical among Heterodera glycines, $H$. hordecalis, $H$. trifolii, $H$. betae, and $H$. schachtii. Other gene sequences, including the ITS region, D2/D3 expansion segments of the $28 \mathrm{~S}$ rDNA gene, and the mtDNA gene, for species discrimination and phylogenetic studies are needed to discriminate Heterodera spp. In one case, D. heterocephalus (T76) was identical to an unidentified Dolichodorus sp. (EF025336) from GenBank based upon 18S sequence data; these two nematodes are likely the same species.

The Hemicycliophora populations T39, T46, and 11-30286 were morphologically identified as Hemicycliophora conida (Zeng et al. $2012 \mathrm{~b}$ ), having a lateral field with transverse anastomoses or breaks of the striae, elongated continuous conical tails with distinct annulations and rounded tips, long vulval lips with a vulval sleeve, a stylet of 78.3 to $90.4 \mu \mathrm{m}$ long, $\mathrm{V}$ (\% distance of vulva from anterior $)=81.5$ to $85.1 \%, \mathrm{R}$ (total annulus number) $=248$ to 269 , and RVan (annulus

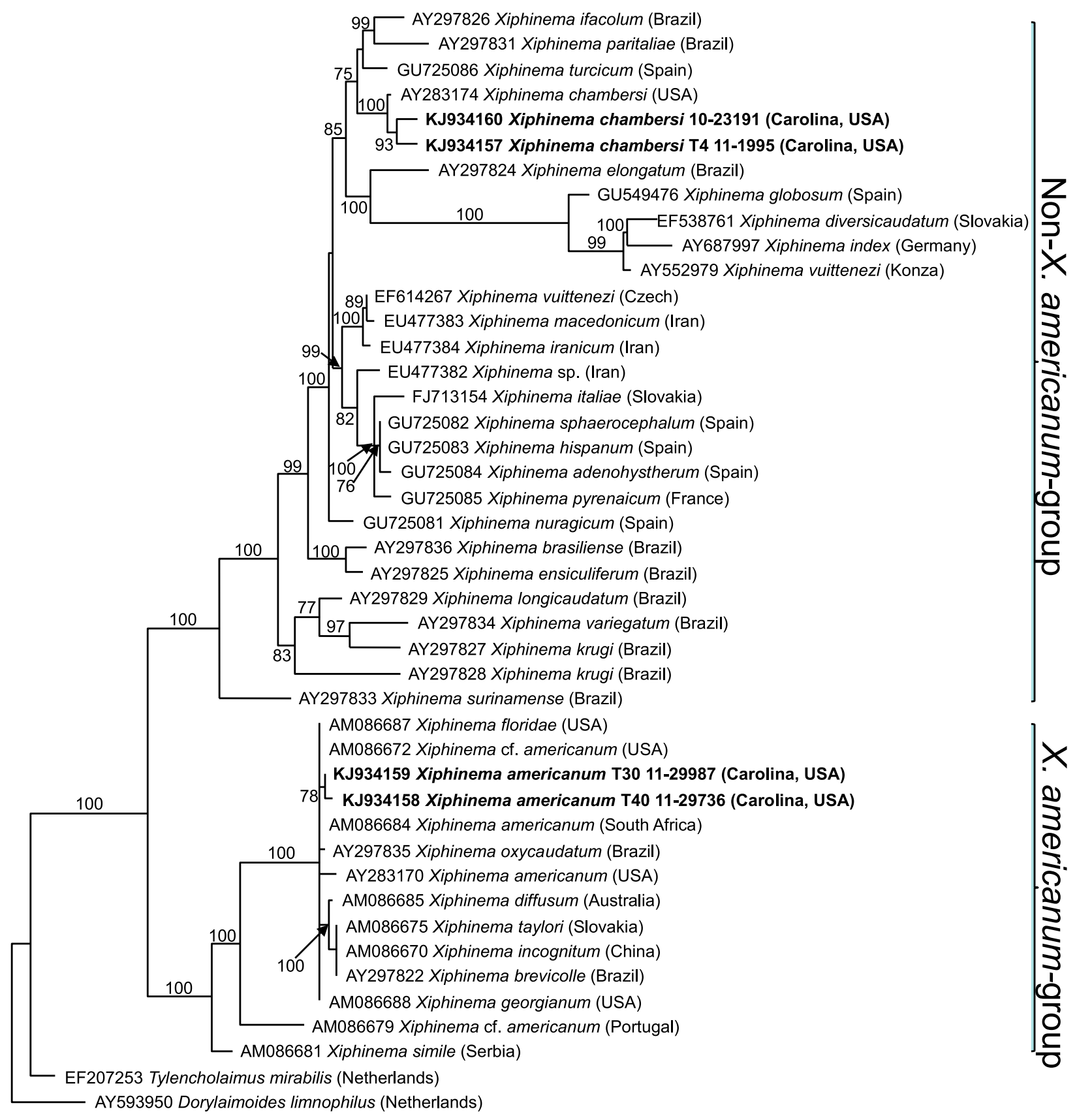

-5 changes

Fig. 4. Phylogenetic relationships among 42 species of Xiphinema nematodes collected from turfgrass sites in North Carolina and South Carolina inferred from the 10,001 replicate of Bayesian analysis deduced from $18 \mathrm{~S}$ rDNA sequences. Two Dorylaimid species sequences are outgroups. Numbers at nodes indicate bootstrap scores $>50 \%$. The phylogenetic tree was generated using MrBayes 3.1.0 (Huelsenbeck and Ronquist 2001). 
number from vulva to anus) of 12 to 18 in females. Molecular analysis showed that the populations T39 and T46 matched $98 \%$ with H. conida (AJ966471) from GenBank. Population 11-30286 was not included in the molecular identification due to lack of DNA. In a recent study, Cordero López et al. (2013) proposed a new species, $H$. wyei, having a lateral field demarked by two faint lines with transverse anastomoses or breaks of the striae, an elongated (not offset) conical tail with distinct annulations and a rounded tip, and long vulval lips with a vulval sleeve in females. It is worth noting that the type specimens of $H$. wyei from turfgrass in Wayne County, NC were provided to the second author for the new species description. The present molecular characterization analysis revealed that the three Hemicycliophora populations (T39, T46, and T57) and $H$. wyei $(\mathrm{KF} 430528)$ were identical $(560 / 560=100 \%)$ in the ITS1 region, although no $18 \mathrm{~S}$ sequence data were available from Cordero López et al. (2013) for comparison. Further morphological and morphometric examination revealed that our populations (T39, T46, and T57) agreed well with $H$. wyei described by Cordero López et al. (2013). Thus, these three study populations and another population (11-30286; Zeng et al. 2012b) are reclassified as $H$. wyei.
Hemicaloosia graminis (T77) was described by Zeng et al. (2012a) while Inserra et al. (2013b) almost simultaneously described $H$. vagisclera (JQ246426) from bermudagrass in Florida. The present molecular analysis revealed that two of our $H$. graminis populations (T14 and T77) matched well (99\%) with H. vagisclera (JQ246426), with only 1 to 2 nucleotide differences in ITS sequence among these three populations. Bayesian analysis demonstrated that these nematodes were in a highly supported $(\mathrm{pp}=100 \%)$ monophyletic clade. Morphological comparison also indicated that there were no significant differences between $H$. graminis and $H$. vagisclera. Thus, they are considered to be the same species, as proposed by Inserra et al. (2013a), but the seniority of the species needs to be further clarified in the future.

The present molecular phylogenetic analysis revealed that clade I within the criconematid group is weakly supported ( $\mathrm{pp}=57 \%)$, consisting of 14 populations belonging to four genera: Criconema, Crossonema, Hemicriconemoides, and Ogma. These genera are not well resolved and available sequence data are very limited. Neither Hemicriconemoides nor Ogma appear to be monophyletic. This is similar to results based on 28S D2/D3 reported by Subbotin et al.

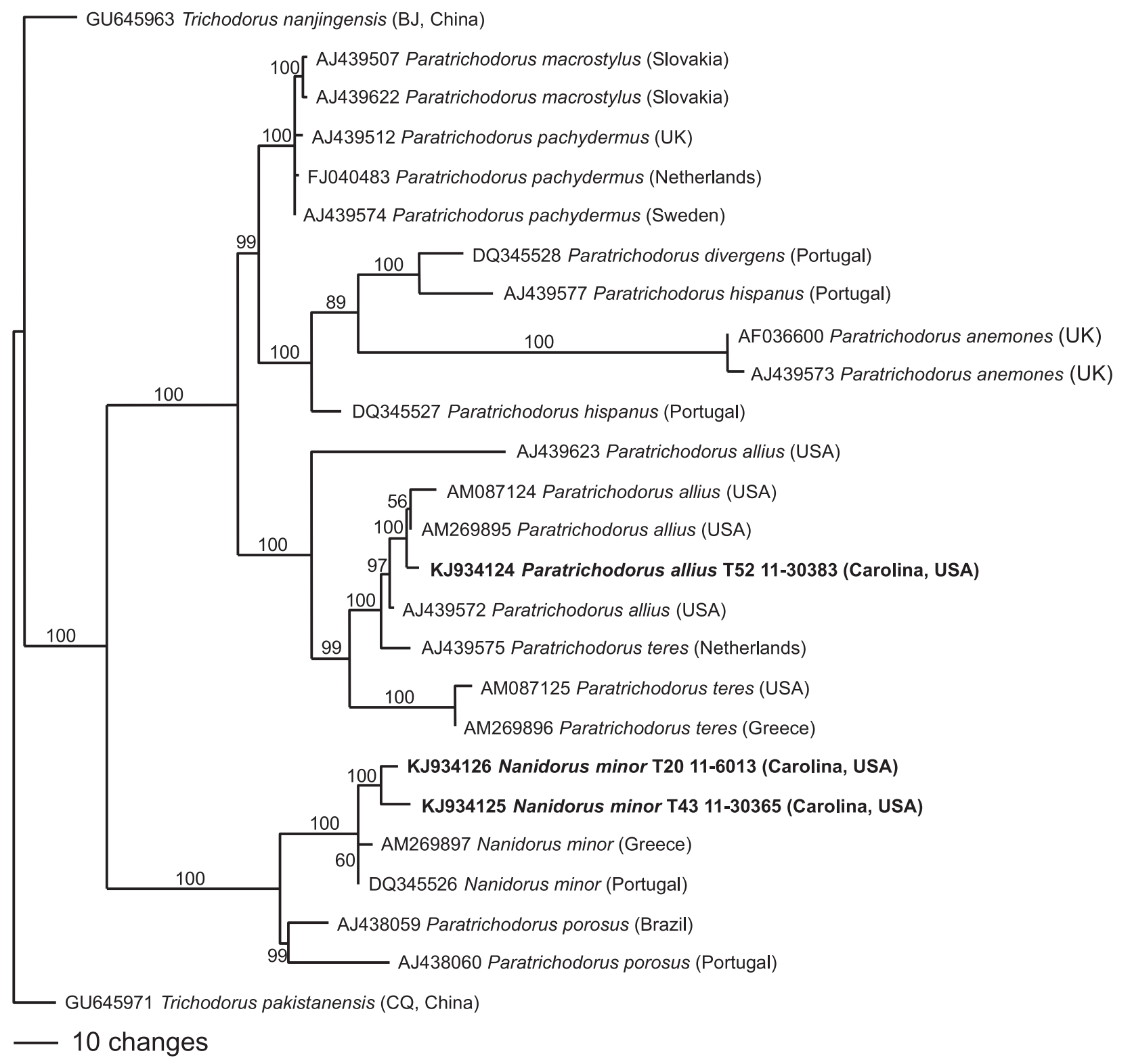

Fig. 5. Phylogenetic relationships among two genera and 24 species of Trichodorid nematodes collected from turfgrass sites in North Carolina and South Carolina inferred from the 10,001 replicate of Bayesian analysis deduced from 18S rDNA sequences. Two Trichodorus spp. sequences are outgroups. Numbers at nodes indicate bootstrap scores $>50 \%$. The phylogenetic tree was generated using MrBayes 3.1.0 (Huelsenbeck and Ronquist 2001). 
(2005). This issue may be resolved by including additional species of the genus in new phylogenetic analysis and reexamining the species identification.

\section{Conclusions}

Analysis of DNA sequences is of importance in confirmation of classical morphology-based identifications of nematode species and in reconstruction of their phylogenetic relationships with available sequences in GenBank. In the present study, the 18S and ITS1 sequence data were employed successfully to support our previous morphological identification of nematodes associated with turfgrasses. Through blastn search based on $18 \mathrm{~S}$ or ITS1 sequence data, the species found during this survey and identified morphologically matched well with data of corresponding species found in GenBank. This study provides basic information on DNA sequence and a comprehensive framework of phylogenetic relationships of plant-parasitic nematodes associated with turfgrass. This is the first report on molecular characterization and phylogeny of plant-parasitic nematodes associated with turfgrasses in North Carolina and South Carolina. Several isolates have not been identified to species level due to lack of sufficient specimens for DNA sequencing and morphological study; thus, more sampling is desired.

\section{Acknowledgments}

This research was supported by a Rounds4 Research grant from the Carolinas Golf Course Superintendents Association. Financial support was also provided by Bayer Environmental Science, Quali-Pro, and Syngenta Crop Protection. Y. Zeng received a co-scholarship of China Scholarship Council and Guangdong Department of Education.

\section{Literature Cited}

Arnold, T. W. 2010. Uninformative parameters and model selection using Akaike's information criterion. J. Wildl. Manage. 74:1175-1178.

Bert, W., Leliaert, F., Vierstraete, A. R., Vanfleteren, J. R., and Borgonie, G. 2008. Molecular phylogeny of the Tylenchina and evolution of the female gonoduct (Nematoda: Rhabditida). Mol. Biol. Evol. 48:728-744.

Blaxter, M. L., De Ley, P., Garey, J. R., Liu, L. X., Scheldeman, P., Vierstraete, A., Vanfleteren, J. R., Mackey, L. Y., Dorris, M., Frisse, L. M., Vida, J. T., and Thomas, W. K. 1998. A molecular evolutionary framework for the phylum Nematoda. Nature 392:71-75.

Byrd, D. W., Jr., Barker, K. R., Ferris, H., Nusbaum, C. J., Griffin, W. E., Small, R. H., and Stone, C. A. 1976. Two semi-automatic elutriators for extracting nematodes and certain fungi from soil. J. Nematol. 8:206-212.

Cherry, T., Szalanski, A. L., Todd, T. C., and Powers, T. O. 1997. The internal transcribed spacer region of Belonolaimus (Nemata: Belonolaimidae). J. Nematol. 29:23-29.

Cordero López, M. A., Robbins, T. R., and Szalanski, A. L. 2013. Taxonomic and molecular identification of Hemicaloosia, Hemicycliophora, Gracilacus and Paratylenchus species (Nematoda: Criconematidae). J. Nematol. 45:145-171.

Decraemer, W. 1995. The Family Trichodoridae: Stubby Root and Virus Vector Nematodes. Kluwer Academic Publishers, Boston.

Dorris, M., De Ley, P., and Blaxter, M. L. 1999. Molecular analysis of nematode diversity and the evolution of parasitism. Parasitol. Today 15:188-193.

Duarte, I. M., De Almeida, M. T. M., Brown, D. J. F., Marques, I., Neilson, R., and Decraemer, W. 2010. Phylogenetic relationships, based on SSU rDNA sequences, among the didelphic genera of the family Trichodoridae from Portugal. Nematology 12:171-180.

Floyd, R., Abebe, E., Papert, A., and Blaxter, M. 2002. Molecular barcodes for soil nematode identification. Mol. Ecol. 11:839-850.

Griffiths, B. S., Donn, S., Neilson, R., and Daniell, T. J. 2006. Molecular sequencing and morphological analysis of a nematode community. Appl. Soil Ecol. 32:325-337.

Gutiérrez-Gutiérrez, C., Cantalapiedra-Navarrete, C., Decraemer, W., Vovlas, N., Prior, T., Palomares-Rius, J., and Castillo, P. 2012. Phylogeny, diversity, and species delimitation in some species of the Xiphinema americanum-group complex (Nematoda: Longidoridae), as inferred from nuclear and mitochondrial DNA sequences and morphology. Eur. J. Plant Pathol. 134:561-597.

Gutiérrez-Gutiérrez, C., Cantalapiedra-Navarrete, C., Montes-Borrego, M., Palomares-Rius, J., and Castillo, P. 2013. Molecular phylogeny of the nematode genus Longidorus (Nematoda: Longidoridae) with description of three new species. Zool. J. Linn. Soc. Lond. 167:473-500.

Gutiérrez-Gutiérrez, C., Palomares-Rius, J., Cantalapiedra-Navarrete, C., Landa, B. B., and Castillo, P. 2010. Molecular analysis and comparative morphology to resolve a complex of cryptic Xiphinema species. Zool. Scr. 39:483-498.

Huelsenbeck, J. P., and Ronquist, F. 2001. Mr Bayes: Bayesian inference of phylogenetic trees. Bioinformatics 17:754-755.

Inserra, R. N., Stanley, J. D., Troccoli, A., Chitambar, J., and Subbotin, S. A. 2013a. Disregarding ZooBank registration results in the unavailability of
Hemicaloosia graminis Zeng et al. 2012 (Nematoda, Tylenchida) under the ICZN Code. ZooKeys 309:71-73

Inserra, R. N., Stanley, J. D., Troccoli, A., Chitambar, J., and Subbotin, S. A. 2013b. Hemicaloosia vagisclera $\mathrm{n}$. sp. (Nematoda: Caloosiidae) from Bermuda grass in Florida and its phylogenetic relationships with other Criconematids. Nematology 15:23-39.

Jenkins, W. R. 1964. A rapid centrifugal-floatation technique for separating nematodes from soil. Plant Dis. Rep. 48:692.

Kanzaki, N., and Futai, K. 2002. A PCR primer set for determination of phylogenetic relationships of Bursapelenchus species within the xylophilus group. Nematology 4:35-41.

Kanzaki, N., and Giblin-Davis, R. M. 2014. Phylogenetic status and morphological characters of Rhabditolaimus anoplophorae (Rhabditida: Diplogastridae). J. Nematol. 46:44-49.

Kumari, S., and Subbotin, S. A. 2012. Molecular characterization and diagnostics of stubby root and virus vector nematodes of the family Trichodoridae (Nematoda: Triplonchida) using ribosomal RNA genes. Plant Pathol. 61: 1021-1031

Larget, B., and Simon, D. L. 1999. Markov Chain Monte Carlo algorithms for the Bayesian analysis of phylogenetic trees. Mol. Biol. Evol. 16:750-759.

Lazarova, S. S., Malloch, G., Oliveira, C. M. G., Hübschen, J., and Neilson, R. 2006. Ribosomal and mitochondrial DNA analyses of Xiphinema americanumgroup populations. J. Nematol. 38:404-410.

McClure, M. A., Nischwitz, C., Skantar, A. M., Schmitt, M. E., and Subbotin, S. A 2012. Root-knot nematodes in golf course greens of the western United States. Plant Dis. 96:635-647.

Milesi, C., Running, S. W., Elvidge, C. D., Dietz, J. B., Tuttle, B. T., and Nemani, R. 2005. Mapping and Modeling the biogeochemical cycling of turf grasses in the United States. Environ. Manage. 36:426-438.

Mullin, P. G., Harris, T. S., and Powers, T. O. 2005. Phylogenetic relationships of Nygolaimina and Dorylaimina (Nematoda: Dorylaimida) inferred from small subunit ribosomal DNA sequences. Nematology 7:59-79.

Neilson, R., Ye, W., Oliveira, C. M. G., Hübschen, J., Robbins, R. T., Brown, D. J. F., and Szalanski, A. L. 2004. Phylogenetic relationships of Longidoridae species (Nematoda: Dorylaimida) from North America inferred from $18 \mathrm{~S}$ rDNA sequence data. Helminthologia 41:209-215.

Nischwitz, C., Skantar, A., Handoo, Z., Hult, M., Schmitt, M., and McClure, M. 2013. Occurrence of Meloidogyne fallax in North America, and molecular characterization of M. fallax and M. minor from U.S. golf course greens. Plant Dis. 97:1424-1430.

Oliveira, C. M. G., Hübschen, J., Brown, D. J. F., Ferraz, L. C. C. B., Wright, F., and Neilson, R. 2004. Phylogenetic relationships among Xiphinema and Xiphidorus nematode species from Brazil inferred from 18S rDNA sequences. J. Nematol. 36:153-159.

Posada, D., and Criandall, K. A. 1998. Modeltest: testing the model of DNA substitution. Bioinformatics 14:817-818.

Salazar, L., Gómez, M., Flores, L., and Gómez-Alpízar, L. 2013. First report of Meloidogyne marylandi infecting Bermudagrass in Costa Rica. Plant Dis. 97 1005.

Shaver, J. B., Agudelo, P., and Martin, S. B. 2013. First Report of stubby root caused by Trichodorus obtusus on zoysiagrass and bermudagrass in South Carolina. Plant Dis. 97:852

Siddiqi, M. R. 2000. Tylenchida: Parasites of Plants and Insects, 2nd ed. CAB International, Wallingford, UK.

Subbotin, S. A., Ragsdale, E. J., Mullens, T., Roberts, P. A., Mundo-Ocampo, M. and Baldwin, J. G. 2008. A Phylogenetic framework for root lesion nematodes of the genus Pratylenchus (Nematoda): Evidence from 18S and D2-D3 expansion fragments of $28 \mathrm{~S}$ ribosomal RNA genes and morphological characters. Mol. Phylogenet. Evol. 48:491-505.

Subbotin, S. A., Sturhan, D., Chizhov, V. N., Vovlas, N., and Baldwin, J. G. 2006. Phylogenetic analysis of Tylenchida Thorne, 1949 as inferred from D2 and D3 expansion fragments of the 28S rRNA gene sequences. Nematology 8:455-474.

Subbotin, S. A., Vierstraete, A., De Ley, P., Rowe, J., Waeyenberge, L., Moens, M., and Vanfleteren, J. R. 2001. Phylogenetic relationships within the cyst-forming nematodes (Nematoda, Heteroderidae) based on analysis of sequences from the ITS region of ribosomal DNA. Mol Phylogenet. Evol. 21:1-16.

Subbotin, S. A., Vovlas, N., Crozzoli, R., Sturhan, D., Lamberti, F., Moens, M., and Baldwin, J. G. 2005. Phylogeny of Criconematina Siddiqi, 1980 (Nematoda: Tylenchida) based on morphology and D2-D3 expansion segments of the 28S-rRNA gene sequences with application of a secondary structure model. Nematology 7:927-944

Turbeville, J. M., Pfeifer, D. M., Feild, K. G., and Raff, R. A. 1991. The phylogenetic status of arthropods, as inferred from 18S rRNA sequences. Mol. Phylogenet. Evol. 8:669-686.

Van Megen, H., Van Den Elsen, S., Holterman, M., Karssen, G., Mooyman, P., Bongers, T., Holovachov, O., Bakker, J., and Helder, J. 2009. A phylogenetic tree of nematodes based on about 1200 full-length small subunit ribosomal DNA sequences. Nematology 11:927-950.

Vovlas, N., Subbotin, S. A., Troccoli, A., Liébanas, G., and Castillo, P. 2008 Molecular phylogeny of the genus Rotylenchus (Nematoda, Tylenchida) and description of a new species. Zool. Scr. 37:521-537. 
Vrain, T. C., Wakarchuk, D. A., Levesque, A. C., and Hamilton, R. I. 1992. Intraspecific rDNA restriction fragment length polymorphism in the Xiphinema americanum group. J. Nematol. 29:250-254.

Ye, W., Giblin-Davis, R. M., Braasch, H., Morris, K., and Thomas, W. K. 2007. Phylogenetic relationships among Bursaphelenchus species (Nematoda: Parasitaphelenchidae) inferred from nuclear ribosomal and mitochondrial DNA sequence data. Mol. Phylogenet. Evol. 43:1185-1197.

Ye, W., Zeng, Y., Tredway, L., Martin S., and Martin M. 2012. Plant-parasitic nematodes in Carolina turfgrass. Carolinas Green March/April:26-28.
Zeng, Y., Ye, W., Tredway, L., Martin, S., and Martin, M. 2012a. Description of Hemicaloosia graminis $\mathrm{n}$. sp. (Nematoda: Caloosiidae) associated with turfgrasses in North and South Carolina, USA. J. Nematol. 44: 134-141.

Zeng, Y., Ye, W., Tredway, L., Martin, S., and Martin, M. 2012b. Taxonomy and morphology of plant-parasitic nematodes associated with turfgrasses in North and South Carolina, USA. Zootaxa 3452:1-46.

Zhuo, K., Hu, M., Wang, H., Tang, Z., Shao, X., and Liao, J. 2011. Identification of Meloidogyne graminis on golf greens. Acta Pratacul. Sin. 20:253-256. 